\title{
PERFORMANCE EVALUATION OF THE SEMICONDUCTOR INDUSTRY BASED ON A METAFRONTIER APPROACH
}

\author{
Ching-Ren CHIU ${ }^{1}$, Chen-Ling FANG ${ }^{2}$, Seng-Su TSANG ${ }^{3}$, Yi-Fen CHEN $^{4}$ \\ ${ }^{1}$ Department of Recreation and Sports Management, University of Taipei, No.101, \\ Sec. 2, Zhongcheng Rd., Taipei City, Taiwan \\ ${ }^{2}$ Department of Finance and Cooperatives Management, National Taipei University, \\ No. 151, University Rd., New Taipei City, Taiwan \\ ${ }^{3}$ Department of Business Administration, National Taiwan University of Science and Technology, \\ No. 43, Sec.4, Keelung Rd., Taipei, Taiwan \\ ${ }^{4}$ Department of Finance, Chihlee University of Technology, No. 313, Sec.1, \\ Wunhua Rd, New Taipei City, Taiwan
}

Received 06 September 2013; accepted 12 October 2014

\begin{abstract}
The semiconductor industry has been regarded as one of the most important industries by Taiwan due to the market share of Taiwan's semiconductor industry in 2011 ranked second worldwide. However, the European debt crisis triggered a global economic recession in 2011, causing Taiwan's output of semiconductors in 2010 and 2011 to show negative growth. This paper will mainly explore, from the performance evaluation perspective, the Malmquist productivity index of the Taiwan's semiconductor industry based on a metafrontier approach. The empirical results show that the European debt crisis in 2011 had an impact on Integrated circuit (IC) design companies and IC manufacturing companies, but that there was no influence on IC packaging and testing companies when measuring static efficiency. From the viewpoint of dynamic productivity performance, the paper finds that the main reason for the negative growth of IC packaging and testing companies and IC design companies came from a backward movement in technical change, but the main reason for the negative growth of IC manufacturing companies derived from a decline in pure technical efficiency.
\end{abstract}

Keywords: semiconductor industry, productivity, directional distance function, metafrontier.

JEL Classification: C54, C61, D20, D70, L25.

\section{Introduction}

Halkos and Tzeremes (2007) point out that the semiconductor industry is crucial to the world, and that the characteristic advantages of this industry are that it is capital intensive, it is technology intensive, it is oriented towards technological integration, and it has a wide

${ }^{\star}$ Corresponding author. E-mail: faling@totalbb.net.tw

This is an Open Access article distributed under the terms of the Creative Commons Attribution License (http://creativecommons. org/licenses/by/4.0/), which permits unrestricted use, distribution, and reproduction in any medium, provided the original author and source are credited. 
range of applications. Since the beginning of the twenty-first century, the semiconductor industry has been considered as the basis of industrial society. The enormous business opportunities derived from the industry are highly regarded by every nation in the world. It is also considered to be one of the industries that has future development potential. The Hsinchu Science Park in Taiwan has made immense contributions toward the promotion of Taiwan's high-tech industries, especially the semiconductor and computer industries. The semiconductor industry in Taiwan consist of, up-, middle- and downstream manufacturing, integrated circuit (IC) design, IC manufacturing, IC packaging and testing companies. The output value of IC design companies are ranking second in the world and the output value of IC manufacturing and IC packaging and testing companies are ranking first in the world. Therefore, Taiwan has become the second-largest semiconductor producer in the world and has successfully transformed its industry structure towards the development of a technologyintensive industry. Taiwan's Ministry of Economic Affairs (MOEA) supports the Technology Development Programme (TDP) and Industrial Technology Development Programme to facilitate technological developments in the domestic industry (Hsu, Chiang 2001; Hsu et al. 2009). However, the burst of the subprime mortgage bubble in 2007 triggered a global financial storm in 2008, which caused a sharp rise in international oil and raw material prices, drove up the pressure for global inflation, and led to a stifling global spending decline. Global semiconductor manufacturers drastically reduced their capital spending, which severely impacted the semiconductor industry in Taiwan. Unfortunately, the Greek debt crisis wrecked the Euro in 2010 after the global financial crisis. This resulted in a global economic depression which swept around the world.

According to the Taiwan Semiconductor Yearbook (2012), after the subprime mortgage meltdown, Taiwan's overall IC industry output value in 2010 (including design, manufacturing, and packaging and testing) was as high as NT\$1,768.6 billion, a growth of 41.5\% from 2009 . However, the European debt crisis caused negative growth in Taiwan's semiconductor industry output in 2011 ( $-11.7 \%$ of the 2010 figure). This was the worst recession for this industry since the subprime mortgage bubble burst in 2007. Analysing this issue from the perspective of industry sectors, we found that there was negative growth in IC design output value in 2011 compared with 2010 and that the output value of IC manufacturing and packaging and testing also declined (both decreased by about $10 \%$ to $15 \%$ ). The market share of Taiwan's semiconductor industry in 2011 ranked second worldwide, following that of the United States. Thus, the importance of Taiwan's semiconductor industry to worldwide economic development is irrefutable (Kao et al. 2011). Consequently, the performance measures of the semiconductor industry in Taiwan have become a very important issue. The directional distance function of the data envelopment analysis (DEA) is regarded as the one of major research tools in assessing performance domain. Because the approach adopts the multiple outputs and inputs to generate the best practice frontier without requiring any assumptions of production function and then identify the reason of inefficient management for inefficient firm manager. It has been widely used in measuring the performance of various industries. Therefore, this paper will mainly explore, from the performance evaluation perspective, the Malmquist productivity index of the Taiwan's semiconductor industry based on a metafrontier approach.

A number of articles have been written about integrating DEA and balanced scorecards (BSC) into R\&D-related applications (Eilat et al. 2006), and assessing intellectual capital 
management in IC design companies (Wu et al. 2006). A considerable amount of literature explores performance evaluations of semiconductor industry; however, the majority of this analyses the management efficiency of certain industry sectors of the semiconductor industry, and a competitive analysis of up-, middle- and downstream manufacturing of the entire semiconductor industry is rarely discussed. The main reason is that the conventional DEA assumes that all manufacturers possess the same production efficiency frontier (production technology) (Nazarko, Šaparauskas 2014), but IC design, IC manufacturing, and IC packaging and testing are different production technologies. Thus, the previous literature only discussed performance evaluations of each individual sector, such as IC design or IC manufacturing, of the semiconductor industry. To solve this problem, O'Donnell et al. (2008) utilize parametric and non-parametric methods to estimate both the metafrontier and the group frontiers, and in their work the technical efficiency measured on the basis of the metafrontier was the decomposed technical efficiency of the group frontiers and the metatechnology ratios (MTR). This study used the metafrontier Malmquist productivity index (MMPI) proposed by O'Donnell et al. (2008) to explore the performance evaluation of Taiwan's semiconductor industry from 2009 to 2011, regarding manufacturers of different production technologies within the semiconductor industry as different groups and discussing group frontier efficiency, metafrontier efficiency, technology gap analysis and the MMPI between three manufacturing groups: IC design, IC manufacturing, and IC packaging and testing. In addition, the conventional MMPI measurement uses the linear programming method to estimate efficiency; this is divided into an input-orientation and an output-orientation and does not consider an input-and-output orientation. Therefore, this study adopts the directional distance function, to take into consideration the fact that outputs are proportionately expanded and that inputs are proportionately reduced, to evaluate semiconductor industry performance.

\section{Research background}

In previous research on the semiconductor industry, there were discussions concerning how the roles of government or industry policymaking affect the semiconductor industry development (Chang, Tsai 2002; Chen, Sewell 1996; Chen, Chang 2004; Shen, Tzeng 2016). There were studies using DEA to estimate the competitive performance of the global semiconductor industry (Kozmetsky, Yue 1998; Hsu 2015). Their research discovered that the USA, Japan, Korea and Taiwan had become global leaders and that the performance of larger-scale semiconductor companies was better. Chen et al. (2006) apply DEA and Malmquist productivity indices to evaluate the relative efficiency and productivity of the six high-tech industries currently developed in Taiwan's Hsinchu Science Park. The results of technical efficiency indicate that the computer industry and semiconductor industry had the best performance while the other four industries, communications, photo-electronics, precision equipment, and biotech, were operated relatively inefficiently. These findings show that developing the semiconductor and computer industries has been a strategic development goal in the Taiwanese government's high-tech development plan for the past two decades. Due to the earnings of the top 30 IC fabless firms accounting for $96 \%$ of all global fabless firms in 2003, Chu et al. (2008) used the DEA to evaluate the operational performance of the top 30 fabless firms and also used the DEA 
efficiency value to evaluate cost effectiveness. Empirical results showed that the top ten firms achieved better operational performance among the 30 leading global fabless firms. Hung and $\mathrm{Lu}$ (2008) applies the DEA approach with the classical radial measure, non-radial efficiency measure and efficiency achievement measure, respectively, to measure the performance differences between the IC packaging/testing firms. The result showed that the overall technical inefficiencies of the firms are primarily due to pure technical inefficiencies rather than scale inefficiencies and indicated that the non-radial efficiency model and the efficiency achievement model can provide more discriminate efficiency measures than classical radial model. Lu (2009) employed and extended the model of Seiford and Zhu (1999) to investigate the R\&D efficiency and marketability of Taiwan's IC design firms. The empirical results showed that the invention efficiency is superior to the R\&D marketability and the number of employees, employee bonuses, and firm age are positively correlated to invention efficiency and R\&D marketability. Lu et al. (2010) developed a two-stage production process including IC capability and IC efficiency to characterize the IC performance of the fable's firms using DEA method. The results showed that IC efficiency is better than IC capability for these fable's firms and suggested these firms should consider mergers and acquisitions to achieve economies of scale.

Lu and Hung (2010) examined the performance of 48 vertically disintegrated firms in Taiwan's IC industry and provided an insight into how each firm acts within the value chain of Taiwan's economy. Their results showed that the IC design firms perform better than IC manufacturing and IC packaging and testing firms, and that a semiconductor firm's scale of size has a great influence on its operating efficiency. They revealed that semiconductor firms must reduce their labour force to improve their operating efficiency, due to employee input congestion. Different from the above-mentioned measurement methods, Liu and Wang (2008) extended the investigation on influence from slack to the Malmquist productivity index. They proposed a non-radial Malmquist productivity index, which is able to eliminate possible inefficiency represented by the non-zero slack to measure the productivity change of IC packaging and testing companies in Taiwan. This approach revealed patterns of productivity change and identified the strategy shifts of individual companies. Lee and Johnson (2011) employed a network DEA proposed by Kao (2009), and then integrated it into the Malmquist productivity index to develop a more detailed decomposition of productivity changes. They revealed that demand fluctuations of the semiconductor manufacturing industry have mainly been caused by decreasing productivity in 1997-1998 and 1999-2000, rather than by technical regression in production capabilities. Chen, Y. and Chen, B. (2011) applies DEA and Malmquist productivity index to explore the operation performances of the Taiwanese wafer fabrication companies from 2004 to 2007. The results showed that if Taiwanese wafer fabrication companies should improve their constant returns to scale (CRS) and VRS efficiencies in order to increase their operation performances. Hung et al. (2014) employed the dynamic DEA model to evaluate the dynamic operating performances of Taiwan's semiconductor industry. The empirical results showed that the operating performances of business group invested semiconductor companies are better than those of non-business invested group semiconductor companies. IC design companies performed better than wafer fabrication companies and these semiconductor companies with high level scopes generally operate better than those with low level scopes. 
In using the conventional DEA approach for efficiency assessment, it is usually assumed that all producers possess the same level of production technology (Beck et al. 2005; Hsiao, Park 2005); however, the assessed DMU usually produces efficiency assessment errors due to the conditions of different production techniques or geographic locations. Therefore, this study explored, under different levels of production technology, the business performance of IC design companies, IC manufacturing companies, and IC packaging and testing companies, and it also evaluated the overall business performance of each company under the construct of a metafrontier function.

\section{Methodology}

\subsection{Metafrontier and group frontiers}

We consider a set of $N$ peer DMUs each with $M$ inputs and $S$ outputs; then let $x_{i j}$ and $y_{r j}$ denote the values of the $i$-th input ( $i \in R_{+}^{M}, R_{+}^{M}$ represent input vector) and the $r$-th output ( $r \in R_{+}^{S}, R_{+}^{S}$ represent output vector) of $\mathrm{DMU}_{j}\left(j \in R_{+}^{N}, R_{+}^{N}\right.$ represent DMUs vector). Chung et al. (1997) proposed the directional distance function, in which allowed outputs are proportionately increased and inputs are proportionately decreased at the same time. The meta-technology set in period $t$ can be represented as follows:

$$
T^{m, t}\left(x^{t}, y^{t}\right)=\left\{\left(x^{t}, y^{t}\right): x^{t} \text { can produce } y^{t}\right\} .
$$

The directional meta-distance function in period $t$ is defined as follows:

$$
\vec{D}^{m, t}\left(x^{t}, y^{t} ;-g_{x}, g_{y}\right)=\sup \left\{\beta^{m, t}:\left(x^{t}-\beta^{m, t} g_{x}, y^{t}+\beta^{m, t} g_{y}\right) \in T^{m, t}\right\},
$$

where the non-zero direction vector $g=\left(-g_{x}, g_{y}\right)$ determines the directions in which inputs and outputs are scaled. The semiconductor industry is divided into $K$ technology sets (sub-groups) due to differences in resources, company property and national policies. The meta-technology set envelops the $K$ group technology set at time period $t$, and then $T^{m, t}=\left\{T^{1, t} \cup T^{2, t} \cup \ldots \cup T^{K, t}\right\}$. The group technology set is represented as follows:

$T^{k, t}\left(x^{t}, y^{t}\right)=\left\{\left(x^{t}, y^{t}\right): x^{t}\right.$ can be used by DMUs in group $k$ to produce $\left.y^{t}\right\}, k=1,2, \ldots, K$.

The $K$ group directional distance function in period $t$ is defined as follows:

$$
\vec{D}^{k, t}\left(x^{t}, y^{t} ;-g_{x}, g_{y}\right)=\sup \left\{\beta^{k, t}:\left(x^{t}-\beta^{k, t} g_{x}, y^{t}+\beta^{k, t} g_{y}\right) \in T^{k, t}\right\}, k=1,2, \ldots, K \text {. }
$$

Due to $T^{m, t}=\left\{T^{1, t} \cup T^{2, t} \cup \ldots \cup T^{K, t}\right\}$, the technical efficiency measured on the basis of the metafrontier is therefore less than those of the group frontiers, as shown by $\mathrm{TE}^{m}\left(x^{t}, y^{t}\right) \leq \mathrm{TE}^{k}\left(x^{t}, y^{t}\right)$. Additionally, the ratio between the technical efficiency of the metafrontier and the group frontiers is referred to as the technology gap ratio $\left(\mathrm{TGR}^{k}\right)$ and can be described as:

$$
0 \leq \operatorname{TGR}^{k}\left(x^{t}, y^{t}\right)=\frac{\operatorname{TE}^{m}\left(x^{t}, y^{t}\right)}{\operatorname{TE}^{k}\left(x^{t}, y^{t}\right)} \leq 1 .
$$


The closer the TGR is to 1, the smaller the gap is, which means the technical efficiency of the group frontiers is closer to the technical efficiency of the metafrontier. Conversely, the smaller the TGR, the greater the gap, which means that the technical efficiency of that group shows a significant lag behind the technical efficiency of the metafrontier. We consider the direction vector $g=\left(-g_{x}=-x, g_{y}=y,-g_{b}=-b\right)$ (Oh 2010; Oh, Lee 2010) before evaluating the directional distance function. In order to calculate the directional meta-distance function and $K$ group directional distance function in period $t$, we need to solve the following two linear programs:

$$
\begin{aligned}
\vec{D}^{m, t} & \left(x_{i o}^{k . t}, y_{r o}^{k . t}\right)=\max \beta_{o}^{m, t} \\
\text { s.t. } & \sum_{k=1}^{K} \sum_{n=1}^{N_{k}} \lambda_{n}^{k, t} x_{i n}^{k, t} \leq\left(1-\beta_{o}^{m, t}\right) x_{i o}^{k, t}, \quad i=1,2, \ldots, M, \\
& \sum_{k=1}^{K} \sum_{n=1}^{N_{k}} \lambda_{n}^{k, t} y_{r n}^{k, t} \geq\left(1+\beta_{o}^{m, t}\right) y_{r o}^{k, t}, \quad r=1,2, \ldots, S, \\
& \lambda_{n}^{k, t} \geq 0, \beta_{o}^{m, t} \text { is free, } n=1,2, \ldots, N_{k} ; \\
\vec{D}^{k, t} & \left(x_{i o}^{k, t}, y_{r o}^{k, t}\right)=\max \beta_{o}^{k, t} \\
\text { s.t. } & \sum_{n=1}^{N_{k}} \mu_{n}^{k, t} x_{i n}^{k, t} \leq\left(1-\beta_{o}^{k, t}\right) x_{i o}^{k, t}, \quad i=1,2, \ldots, M, \\
& \sum_{n=1}^{N_{k}} \mu_{n}^{k, t} y_{r n}^{k, t} \geq\left(1+\beta_{o}^{k, t}\right) y_{r o}^{k, t}, \quad r=1,2, \ldots, S, \\
& \mu_{n}^{k, t} \geq 0, \beta_{o}^{k, t} \text { is free, } n=1,2, \ldots, N_{k},
\end{aligned}
$$

where $\lambda_{n}^{k}$ and $\mu_{n}^{k}$ represent the intensity variables corresponding to the production process of the meta-technology set and the group technology set, respectively and $N_{1}+N_{2}+\cdots+N_{K}=N$. The technical efficiency of $\mathrm{DMU}_{o}^{k, t}$ measured on the basis of the metafrontier and the group frontiers is defined as $\mathrm{TE}^{m}=1-\beta_{o}^{m, t}$ and $\mathrm{TE}^{k}=1-\beta_{o}^{k, t}$ within time $t$, and the technical efficiency may be between zero and one.

\subsection{MMPI and GMPI}

The above-mentioned technical efficiency analysis is measured from a static point of view of the semiconductor industry's operational performance within the same period. However, the movement of the relative efficiency of the semiconductor industry over different periods of time is also an important reference in management decision-making (Mahadevan 2002). Therefore, this paper adopts the concept of the Malmquist productivity index (MPI) from Caves et al. (1982) to measure cross-period productivity change; thus, the MPI measured on the basis of the metafrontier regarding period $t$ and period $t+1$ as the base year, is defined as:

$$
\mathrm{MMPI}^{m, t}=\frac{\mathrm{TE}^{m, t}\left(x^{t+1}, y^{t+1}\right)}{\mathrm{TE}^{m, t}\left(x^{t}, y^{t}\right)} ;
$$




$$
\mathrm{MMPI}^{m, t+1}=\frac{\mathrm{TE}^{m, t+1}\left(x^{t+1}, y^{t+1}\right)}{\mathrm{TE}^{m, t+1}\left(x^{t}, y^{t}\right)} .
$$

To solve the problem of the choice of the base year, Färe et al. (1994) and Chen and Yang (2011) defined the geometric mean of the MMPI of two periods as

$$
\begin{aligned}
& \mathrm{MMPI}^{m, t, t+1}=\left[\frac{\mathrm{TE}^{m, t}\left(x^{t+1}, y^{t+1}\right)}{\mathrm{TE}^{m, t}\left(x^{t}, y^{t}\right)} \times \frac{\mathrm{TE}^{m, t+1}\left(x^{t+1}, y^{t+1}\right)}{\mathrm{TE}^{m, t+1}\left(x^{t}, y^{t}\right)}\right]^{\frac{1}{2}}= \\
& \frac{\mathrm{TE}^{m, t+1}\left(x^{t+1}, y^{t+1}\right)}{\mathrm{TE}^{m, t}\left(x^{t}, y^{t}\right)}\left[\frac{\mathrm{TE}^{m, t}\left(x^{t}, y^{t}\right)}{\mathrm{TE}^{m, t+1}\left(x^{t+1}, y^{t+1}\right)} \times \frac{\mathrm{TE}^{m, t}\left(x^{t+1}, y^{t+1}\right)}{\mathrm{TE}^{m, t+1}\left(x^{t}, y^{t}\right)}\right]^{\frac{1}{2}}= \\
& \frac{\mathrm{TE}^{m, t+1}\left(x^{t+1}, y^{t+1}\right)}{\mathrm{TE}^{m v, t}\left(x^{t}, y^{t}\right)} \times \frac{\mathrm{SE}^{m v, t+1}\left(x^{t+1}, y^{t+1}\right)}{\mathrm{SE}^{m v, t}\left(x^{t}, y^{t}\right)}\left[\frac{\mathrm{TE}^{m, t}\left(x^{t}, y^{t}\right)}{\mathrm{TE}^{m, t+1}\left(x^{t+1}, y^{t+1}\right)} \times \frac{\mathrm{TE}^{m, t}\left(x^{t+1}, y^{t+1}\right)}{\mathrm{TE}^{m, t+1}\left(x^{t}, y^{t}\right)}\right]^{\frac{1}{2}}= \\
& \mathrm{TEC}^{m v, t, t+1} \times \mathrm{SEC}^{m, t, t+1} \times \mathrm{TC}^{m, t, t+1},
\end{aligned}
$$

where $\mathrm{TEC}^{m v, t, t+1}$ represents the pure technical efficiency change measured on the basis of the metafrontier under variable returns to scale (VRS). If the value is larger than unity, this means that the pure technical efficiency of a specific firm has progressed from period $t$ to period $t+1$. The SEC ${ }^{m v, t, t+1}$ signifies the scale efficiency change measured on the basis of the metafrontier under VRS and the value is close to unity, therefore the production scale of a specific firm is the closest to the optimum metafrontier production scale in period $t$ and $t+1$. The TEC ${ }^{m, t, t+1}$ expresses the technical efficiency change measured on the basis of the metafrontier, and the value is equal to $\mathrm{TEC}^{m v, t, t+1} \times \mathrm{SEC}^{m v, t, t+1}$ TC $^{m, t, t+1}$ represents the technical change measured on the basis of the metafrontier, and a value larger than unity shows that the technology of a specific firm in period $t+1$ is greater than in period $t$ (technical progress). Furthermore, if the MPI is measured on the basis of the group frontier, then the group Malmquist productivity index (GMPI) is defined as:

$$
\begin{aligned}
& \mathrm{GMPI}^{k, t, t+1}=\left[\frac{\mathrm{TE}^{k, t}\left(x^{t+1}, y^{t+1}\right)}{\mathrm{TE}^{k, t}\left(x^{t}, y^{t}\right)} \times \frac{\mathrm{TE}^{k, t+1}\left(x^{t+1}, y^{t+1}\right)}{\mathrm{TE}^{k, t+1}\left(x^{t}, y^{t}\right)}\right]^{\frac{1}{2}}= \\
& \frac{\mathrm{TE}^{k, t+1}\left(x^{t+1}, y^{t+1}\right)}{\mathrm{TE}^{k, t}\left(x^{t}, y^{t}\right)}\left[\frac{\mathrm{TE}^{k, t}\left(x^{t}, y^{t}\right)}{\mathrm{TE}^{k, t+1}\left(x^{t+1}, y^{t+1}\right)} \times \frac{\mathrm{TE}^{k, t}\left(x^{t+1}, y^{t+1}\right)}{\mathrm{TE}^{k, t+1}\left(x^{t}, y^{t}\right)}\right]^{\frac{1}{2}}= \\
& \frac{\mathrm{TE}^{k v, t+1}\left(x^{t+1}, y^{t+1}\right)}{\mathrm{TE}^{k v, t}\left(x^{t}, y^{t}\right)} \times \frac{\mathrm{SE}^{k v, t+1}\left(x^{t+1}, y^{t+1}\right)}{\mathrm{SE}^{k v, t}\left(x^{t}, y^{t}\right)}\left[\frac{\mathrm{TE}^{k, t}\left(x^{t}, y^{t}\right)}{\mathrm{TE}^{k, t+1}\left(x^{t+1}, y^{t+1}\right)} \times \frac{\mathrm{TE}^{k, t}\left(x^{t+1}, y^{t+1}\right)}{\mathrm{TE}^{k, t+1}\left(x^{t}, y^{t}\right)}\right]^{\frac{1}{2}}= \\
& \mathrm{TEC}^{k v, t, t+1} \times \mathrm{SEC}^{k v, t, t+1} \times \mathrm{TC}^{k, t, t+1}=\mathrm{TEC}^{k, t, t+1} \times \mathrm{TC}^{k, t, t+1},
\end{aligned}
$$


where $\mathrm{TEC}^{k v, t, t+1}$ represents the pure technical efficiency change measured on the basis of the group frontier under VRS. A value larger than unity expresses the pure technical efficiency of a specific firm that progresses from period $t$ to period $t+1$. SEC ${ }^{k v, t, t+1}$ signifies the scale efficiency change measured on the basis of the group frontier under VRS, and the value is close to unity, which means production scale of a specific firm is close to the optimum group frontier production scale in period $t$ and $t+1$. TEC ${ }^{k, t, t+1}$ expresses the technical efficiency change measured on the basis of the group frontier, and its value is equal to $\mathrm{TEC}^{k v, t, t+1} \times \mathrm{SEC}^{k v, t, t+1}$. $\mathrm{TC}^{k, t, t+1}$ represents the technical change measured on the basis of the group frontier; a value larger than unity shows the technology of specific firm in period $t+1$ is greater than in period $t$.

According to Eq. (5) and Eq. (10), TEC Tt,t+1 $^{m}$ can be further decomposed as:

$$
\begin{aligned}
& \mathrm{TEC}^{m, t, t+1}=\frac{\mathrm{TE}^{m, t+1}\left(x^{t+1}, y^{t+1}\right)}{\mathrm{TE}^{m, t}\left(x^{t}, y^{t}\right)}= \\
& \frac{\mathrm{TE}^{k, t+1}\left(x^{t+1}, y^{t+1}\right) \times \mathrm{TGR}^{k, t+1}\left(x^{t+1}, y^{t+1}\right)}{\mathrm{TE}^{k, t}\left(x^{t}, y^{t}\right) \times \mathrm{TGR}^{k, t}\left(x^{t}, y^{t}\right)}= \\
& \frac{\mathrm{TE}^{k v, t+1}\left(x^{t+1}, y^{t+1}\right) \times \mathrm{SE}^{k v, t+1}\left(x^{t+1}, y^{t+1}\right) \times \mathrm{TGR}^{k, t+1}\left(x^{t+1}, y^{t+1}\right)}{\mathrm{TE}^{k v, t}\left(x^{t}, y^{t}\right) \times \mathrm{SE}^{k v, t}\left(x^{t}, y^{t}\right) \times \mathrm{TGR}^{k, t}\left(x^{t}, y^{t}\right)}= \\
& \mathrm{TEC}^{k v, t, t+1} \times \mathrm{SEC}^{k v, t, t+1} \times \frac{\mathrm{TGR}^{k, t+1}\left(x^{t+1}, y^{t+1}\right)}{\mathrm{TGR}^{k, t}\left(x^{t}, y^{t}\right)}= \\
& \mathrm{TEC}^{k v, t, t+1} \times \mathrm{SEC}^{k v, t, t+1} \times \mathrm{CUT}^{k, t, t+1},
\end{aligned}
$$

where CUT" ${ }^{k, t+1+1}$ is called "catch-up in technology" and is measured on the basis of the group frontier. A value larger than unity means that the technical efficiency of the group frontiers is much closer to the technical efficiency of the metafrontier in period $t$ and $t+1$.

Additionally,

$$
\begin{aligned}
& \mathrm{CUT}^{k, t, t+1}=\frac{\mathrm{TGR}^{k, t+1}\left(x^{t+1}, y^{t+1}\right)}{\mathrm{TGR}^{k, t}\left(x^{t}, y^{t}\right)}=\frac{\mathrm{TE}^{m, t+1}\left(x^{t+1}, y^{t+1}\right)}{\mathrm{TE}^{m, t}\left(x^{t}, y^{t}\right)} \times \frac{\mathrm{TE}^{k, t}\left(x^{t}, y^{t}\right)}{\mathrm{TE}^{k, t+1}\left(x^{t+1}, y^{t+1}\right)}= \\
& \frac{\mathrm{TE}^{m v, t+1}\left(x^{t+1}, y^{t+1}\right) \times \mathrm{SE}^{m v, t+1}\left(x^{t+1}, y^{t+1}\right)}{\mathrm{TE}^{m v, t}\left(x^{t}, y^{t}\right) \times \mathrm{SE}^{m v, t}\left(x^{t}, y^{t}\right)} \times \frac{\mathrm{TE}^{k v, t}\left(x^{t}, y^{t}\right) \times \mathrm{SE}^{k v, t}\left(x^{t}, y^{t}\right)}{\mathrm{TE}^{k v, t+1}\left(x^{t+1}, y^{t+1}\right) \times \mathrm{SE}^{k v, t+1}\left(x^{t+1}, y^{t+1}\right)}= \\
& \frac{\mathrm{TE}^{m v, t+1}\left(x^{t+1}, y^{t+1}\right) / \mathrm{TE}^{k v, t+1}\left(x^{t+1}, y^{t+1}\right)}{\mathrm{TE}^{m v, t}\left(x^{t}, y^{t}\right) / \mathrm{TE}^{k v, t}\left(x^{t}, y^{t}\right)} \times \frac{\mathrm{SE}^{m v, t+1}\left(x^{t+1}, y^{t+1}\right) / \mathrm{SE}^{k v, t+1}\left(x^{t+1}, y^{t+1}\right)}{\mathrm{SE}^{m v, t}\left(x^{t}, y^{t}\right) / \mathrm{SE}^{k v, t}\left(x^{t}, y^{t}\right)}= \\
& \mathrm{CUE}^{k v, t, t+1} \times \mathrm{CUS}^{k, t, t+1},
\end{aligned}
$$

where CUE ${ }^{k v, t, t+1}$ represents the "catch-up in pure technical efficiency under VRS". A value larger than unity represents the increase in pure technical efficiency of a specific firm in period $t+1$ is greater than in period $t$. CUS ${ }^{k, t, t+1}$ is referred to as "catch-up in scale efficiency"; if its value is close to unity, this indicates that the production scale of a specific firm in period 
$t+1$ is close to the optimum metafrontier production scale than in period $t$.

$$
\mathrm{TC}^{m, t, t+1}=\mathrm{TC}^{k, t, t+1} \times \frac{\mathrm{TC}^{m, t, t+1}}{\mathrm{TC}^{k, t, t+1}}=\mathrm{TC}^{k, t, t+1} \times \mathrm{PTC}^{k, t, t+1},
$$

where $\mathrm{TC}^{k, t, t+1}$ is the technical change and $\mathrm{PTC}^{k, t, t+1}$ is the potential technical change measured on the basis of the group frontier; if $\mathrm{PTC}^{k, t, t+1}$ is larger than unity, the technical progress of the metafrontier is superior to that of the group frontier. Consequently, if we integrate Eqs (12), (13) and (14), Eq. (10) can be substituted into Eq. (15):

$$
\begin{aligned}
& \mathrm{MMPI}^{m, t, t+1}=\mathrm{TEC}^{k v, t, t+1} \times \mathrm{SEC}^{k v, t, t+1} \times \mathrm{CUT}^{k, t, t+1} \times \mathrm{TC}^{k, t, t+1} \times \mathrm{PTC}^{k, t, t+1}= \\
& \mathrm{GMPI}^{k, t, t+1} \times \mathrm{CUT}^{k, t, t+1} \times \mathrm{PTC}^{k, t, t+1}=\mathrm{GMPI}^{k, t, t+1} \times \mathrm{CUE}^{k v, t, t+1} \times \mathrm{CUS}^{k, t, t+1} \times \mathrm{PTC}^{k, t, t+1} .
\end{aligned}
$$

\section{Empirical analysis}

\subsection{Research subject and data source}

The empirical research focuses on the technical efficiency and productivity of the metafrontier and group frontiers for Taiwan's semiconductor industry during 2009 to 2011. Based on data in the semiconductor manufacturer yearbook, the industry is divided into IC design, IC manufacturing, and IC packaging and testing. In order to obtain information fairly and consistently, this study focused on semiconductor manufacturers that were listed on the stock market and over the counter (OTC) market. In order to conform the homogeneity of sampled companies during research period, we selected 77 IC design companies, 10 IC manufacturing companies, and 24 IC packaging and testing companies - a total of 111 companies - that were all published by the Taiwan Stock Exchange (TWSE) and the databank of the Taiwan Economic Journal (TEJ), as our research samples.

Meng et al. (2006) showed that R\&D activity, sales growth and the market value of firms exist in a positive relationship. R\&D expenses were used as a proxy for innovation inputs for R\&D activity (Graves, Langowitz 1996; Wang, Huang 2007). Regardless of whether manufacturing or non-manufacturing firms are involved, $\mathrm{R} \& \mathrm{D}$ and human capital have a significant impact on productivity and performance (O’Mahony, Vecchi 2009). Human capital is an important asset, helping firms engage in production activities, and, for this reason, the number of employees should be considered as an innovation input (Sterlacchini 1999). Because the semiconductor industry is a high-tech one, Kozmetsky and Yue (1998) took fixed assets and the cost of sales into account when considering innovation input. Consequently, we chose fixed assets $\left(x_{1}\right)$, number of employees $\left(x_{2}\right), \mathrm{R} \& \mathrm{D}$ expenses $\left(x_{3}\right)$, and cost of sales $\left(x_{4}\right)$ as input variables, and net sales $\left(y_{1}\right)$ and market value $\left(y_{2}\right)$ as output variables. Table 1 shows the definitions of the input and output variables. Other related studies that adopt similar measures are listed in the references column.

Tables 2 contains the descriptive statistics of the input and output variables for IC design, IC manufacturing, and IC packaging and testing companies for, respectively, each year from 2009 to 2011. From the table, we see that although the lowest number of companies is in IC manufacturing, the means of the input and output variables are higher and the 
magnitude of the standard deviations is greater than the same figures for IC design and IC packaging and testing companies, except for the number of employees. This indicates that IC manufacturing has the highest entry threshold in the semiconductor industry. IC design companies, on the other hand, do not require high capital spending but has high output value. Table 3 presents the descriptive statistics of the input and output variables of the semiconductor industry from 2009 to 2011. It shows that the fixed assets $\left(x_{1}\right)$, employee numbers $\left(x_{2}\right), \mathrm{R} \& \mathrm{D}$ expenses $\left(x_{3}\right)$ and cost of sales $\left(x_{4}\right)$ in 2011 were clearly higher than in 2009 and 2010; however, net sales $\left(y_{1}\right)$ and market value $\left(y_{2}\right)$ are highest in the year 2010. After the global financial tsunami in 2008, the global economy slowly recovered from 2009 to 2010, but the European debt storm caused a global economic collapse in 2011. Comparing the results from Table 3, we find that the recovery period in the global economy exerted a significant impact on net sales $\left(y_{1}\right)$ and market values $\left(y_{2}\right)$ in the semiconductor industry. During the downturn in the global economy, the semiconductor industry, unlike other industries, needed to increase its fixed assets $\left(x_{1}\right)$, employee numbers $\left(x_{2}\right), \mathrm{R} \& \mathrm{D}$ expenses $\left(\mathrm{x}_{3}\right)$ and cost of sales $\left(x_{4}\right)$ continuously.

Table 1. Measures of inputs and outputs

\begin{tabular}{|c|c|c|}
\hline Dimension & Variables & References \\
\hline \multirow{4}{*}{ Inputs } & $\begin{array}{l}\left(x_{1}\right) \text { Fixed assets (unit: million NT\$): } \\
\text { includes land, houses, buildings, machinery } \\
\text { and other equipment owned by companies. }\end{array}$ & $\begin{array}{l}\text { Chen et al. (2006); Chu et al. (2008); } \\
\text { Hung and Lu (2008); Kozmetsky and } \\
\text { Yue (1998); Thore et al. (1996) }\end{array}$ \\
\hline & $\begin{array}{l}\left(x_{2}\right) \text { Employees: the count of staff in a } \\
\text { company }\end{array}$ & $\begin{array}{l}\text { Chen et al. (2006); Hung and Lu (2008); } \\
\text { Thore et al. (1996) }\end{array}$ \\
\hline & $\begin{array}{l}\left(x_{3}\right) \text { R\&D expenses (unit: million NT\$): } \\
\text { costs of research and development activities } \\
\text { arising from personnel, transaction, } \\
\text { maintenance, materials and other fees }\end{array}$ & Chu et al. (2008); Thore et al. (1996) \\
\hline & $\begin{array}{l}\left(x_{4}\right) \text { Cost of sales (unit: million NT\$): to the } \\
\text { cost of the initial inventory, add sales over } \\
\text { the given period, and then subtract the cost } \\
\text { of the final inventory }\end{array}$ & $\begin{array}{l}\text { Chen et al. (2006); Hung and Lu (2008); } \\
\text { Thore et al. (1996) }\end{array}$ \\
\hline \multirow{2}{*}{ Output } & $\begin{array}{l}\left(y_{1}\right) \text { Net sales (unit: million NT\$): the } \\
\text { operating income after deducting for } \\
\text { operating expenses }\end{array}$ & Hung and Lu (2008); Thore et al. (1996) \\
\hline & $\begin{array}{l}\left(y_{2}\right) \text { Market value (unit: million NT\$): the } \\
\text { product of the weighted average stock price } \\
\text { and the outstanding shares }\end{array}$ & Hung and Lu (2008); Thore et al. (1996) \\
\hline
\end{tabular}


Table 2. Descriptive statistics of the inputs and outputs from 2009 to 2011

\begin{tabular}{|c|c|c|c|c|c|c|c|c|}
\hline & & & $x_{1}$ & $x_{2}$ & $x_{3}$ & $x_{4}$ & $y_{1}$ & $y_{2}$ \\
\hline \multirow{6}{*}{$\begin{array}{l}\text { IC design } \\
\text { (77 companies) }\end{array}$} & \multirow{2}{*}{2009} & Mean & 429 & 371 & 747 & 2,757 & 4,587 & 16,305 \\
\hline & & Std. Dev. & 947 & 614 & 2,795 & 6,321 & 13,678 & 68,939 \\
\hline & \multirow{2}{*}{2010} & Mean & 469 & 407 & 761 & 3,280 & 5,134 & 12,901 \\
\hline & & Std. Dev. & 1,040 & 730 & 2,692 & 7,381 & 13,860 & 52,111 \\
\hline & \multirow{2}{*}{2011} & Mean & 507 & 442 & 748 & 3,060 & 4,464 & 8,338 \\
\hline & & Std. Dev. & 1,219 & 881 & 2,470 & 6,886 & 11,182 & 36,292 \\
\hline \multirow{6}{*}{$\begin{array}{l}\text { IC manufacturing } \\
\text { (10 companies) }\end{array}$} & \multirow{2}{*}{2009} & Mean & 68,651 & 6,487 & 4,380 & 44,921 & 57,409 & 228,714 \\
\hline & & Std. Dev. & 77,399 & 7,367 & 6,162 & 46,487 & 82,999 & 484,674 \\
\hline & \multirow{2}{*}{2010} & Mean & 86,659 & 7,833 & 5,783 & 55,368 & 82,349 & 235,556 \\
\hline & & Std. Dev. & 109,940 & 9,862 & 8,407 & 59,868 & 117,913 & 537,599 \\
\hline & \multirow{2}{*}{2011} & Mean & 94,216 & 7,982 & 6,576 & 56,957 & 74,646 & 227,165 \\
\hline & & Std. Dev. & 139,237 & 9,961 & 9,607 & 65,041 & 121,277 & 580,910 \\
\hline \multirow{6}{*}{$\begin{array}{l}\text { IC packaging } \\
\text { and testing } \\
\text { ( } 24 \text { companies) }\end{array}$} & \multirow{2}{*}{2009} & Mean & 9,396 & 3,343 & 297 & 8,717 & 10,690 & 21,909 \\
\hline & & Std. Dev. & 16,982 & 6,324 & 742 & 15,770 & 19,976 & 40,326 \\
\hline & \multirow{2}{*}{2010} & Mean & 11,189 & 4,552 & 447 & 13,325 & 16,870 & 23,813 \\
\hline & & Std. Dev. & 21,056 & 9,955 & 1,239 & 30,301 & 38,376 & 44,734 \\
\hline & \multirow{2}{*}{2011} & Mean & 12,000 & 4,662 & 520 & 13,398 & 16,437 & 17,769 \\
\hline & & Std. Dev. & 23,341 & 10,503 & 1,440 & 30,627 & 37,701 & 37,602 \\
\hline
\end{tabular}

Table 3. Descriptive statistics of the inputs and outputs for the 111 semiconductor companies from 2009 to 2011

\begin{tabular}{|c|l|c|c|c|c|c|c|}
\hline $\begin{array}{c}\text { Semiconductor industry } \\
\text { (111 companies) }\end{array}$ & & $x_{1}$ & $x_{2}$ & $x_{3}$ & $x_{4}$ & $y_{1}$ & $y_{2}$ \\
\hline \multirow{3}{*}{2009} & Mean & 8,514 & 1,564 & 977 & 7,844 & 10,665 & 36,653 \\
\cline { 2 - 9 } & Std. Dev. & 31,209 & 4,202 & 3,184 & 20,448 & 32,544 & 168,727 \\
\cline { 2 - 9 } & Min & 2 & 27 & 5 & 20 & 31 & 115 \\
\cline { 2 - 9 } & Max & 273,675 & 29,500 & 24,185 & 166,414 & 295,742 & $1,670,725$ \\
\hline \multirow{3}{*}{2010} & Mean & 10,552 & 1,972 & 1,145 & 10,145 & 14,628 & 35,320 \\
\cline { 2 - 9 } & Std. Dev. & 42,166 & 6,066 & 3,725 & 27,899 & 46,701 & 179,841 \\
\cline { 2 - 9 } & Min & 2 & 22 & 5 & 33 & 48 & 122 \\
\cline { 2 - 8 } & Max & 388,444 & 48,900 & 29,707 & 212,484 & 419,538 & $1,839,616$ \\
\hline \multirow{5}{*}{2011} & Mean & 11,434 & 2,034 & 1,224 & 10,151 & 13,375 & 30,091 \\
\cline { 2 - 8 } & Std. Dev. & 50,652 & 6,306 & 3,980 & 29,178 & 45,983 & 188,364 \\
\cline { 2 - 8 } & Min & 2 & 24 & 2 & 18 & 30 & 126 \\
\cline { 2 - 8 } & Max & 490,375 & 51,400 & 33,830 & 232,937 & 427,081 & $1,964,450$ \\
\hline
\end{tabular}




\subsection{Efficiency assessment}

The conventional DEA approach assumes that the all DMUs being evaluated are equipped with similar levels of technology. This assumption, however, may not correspond to reality, and the corresponding results would provide an inappropriate efficiency frontier. Therefore, a nonparametric statistical test, like the Kruskal-Wallis test, is suitable to examine the technology frontier differences between the IC design, manufacturing, and packaging and testing companies. The null hypothesis represents that the three samples are from identical populations. The result reveals that the Kruskal-Wallis test values for 2009 to 2011 are 8.439, 8.035, and 6.504, respectively and that the null hypothesis is rejected at the $5 \%$ significance level. The analytical results led us to infer that the three samples belong to different technology frontiers and that technology gaps exist among them (Huang et al. 2012). Using formulas (6) and (7), we calculated the metafrontier efficiency $\left(1-\vec{D}^{m, t}\left(x_{t}, y_{t}\right)\right)$ of the overall semiconductor industry from 2009 to 2011 and the efficiency $\left(1-\vec{D}^{k, t}(x, y)\right)$ within the IC design, manufacturing, and packaging and testing companies. We then used formula (5) to calculate the technology gap ratio (TGR).

Table 4 shows that the metafrontier efficiencies of the IC design companies and the IC manufacturing companies performed the best in 2010, but the metafrontier efficiencies of the IC design companies and the IC manufacturing companies performed the worst in 2011. The IC packaging and testing companies performed the best in 2009. This means, in terms of measuring by metafrontier, that the European debt storm in 2011 had an impact on the IC design companies and IC manufacturing companies but that there was no influence on the IC packaging and testing companies. In addition, we found that the IC manufacturing companies underperformed against the IC design companies and IC packaging and testing companies, when the metafrontier was regarded as the evaluation basis, from 2009 to 2011. In terms of the TGR, IC design companies had the largest TGR from 2009 to 2011, which means that IC design companies have small efficiency gaps between the metafrontier and group frontier. These companies are followed by IC packaging and testing companies, while IC manufacturing companies have the largest efficiency gaps.

Table 4. The average technical efficiency of the metafrontier and group frontiers, and TGR

\begin{tabular}{|c|c|c|c|c|}
\hline \multirow{2}{*}{ Year } & $\begin{array}{c}\text { The technical efficiency of the metafrontier } \\
\text { and group frontiers, and TGR }\end{array}$ & $\begin{array}{c}\text { IC } \\
\text { design }\end{array}$ & IC manufacturing & $\begin{array}{c}\text { IC packaging } \\
\text { and testing }\end{array}$ \\
\hline \multirow{3}{*}{2009} & $\mathrm{TE}^{m, t}\left(x^{t}, y^{t}\right)$ & 0.884 & 0.848 & 0.921 \\
\cline { 2 - 5 } & $\mathrm{TE}^{k, t}\left(x^{t}, y^{t}\right)$ & 0.889 & 0.946 & 0.945 \\
\cline { 2 - 5 } & $\mathrm{TGR}$ & 0.995 & 0.895 & 0.973 \\
\hline \multirow{3}{*}{2010} & $\mathrm{TE}^{m, t}\left(x^{t}, y^{t}\right)$ & 0.898 & 0.879 & 0.890 \\
\cline { 2 - 5 } & $\mathrm{TE}^{k, t}\left(x^{t}, y^{t}\right)$ & 0.904 & 0.981 & 0.921 \\
\cline { 2 - 5 } & $\mathrm{TGR}$ & 0.993 & 0.896 & 0.966 \\
\hline \multirow{3}{*}{2011} & $\mathrm{TE}^{m, t}\left(x^{t}, y^{t}\right)$ & 0.883 & 0.808 & 0.890 \\
\cline { 2 - 5 } & $\mathrm{TE}^{k, t}\left(x^{t}, y^{t}\right)$ & 0.886 & 0.958 & 0.924 \\
\cline { 2 - 5 } & $\mathrm{TGR}$ & 0.996 & 0.841 & 0.963 \\
\hline
\end{tabular}


From a methodological perspective, the efficiency score obtained with the directional distance function and conventional DEA approach (see the input-oriented CCR model of Charnes et al. 1978) will be different. The descriptive statistics for the metafrontier efficiencies obtained using both approaches appear in Table 5. The result shows that the mean metafrontier efficiencies in the CCR model are lower than that obtained using the directional distance function for all the years. However, the standard deviations and ranges of the metafrontier efficiencies for the CCR model are higher than the corresponding values obtained using the directional distance function. These results show that the metafrontier efficiencies for the CCR model will be underestimated and that the metafrontier efficiencies for the CCR model fluctuate widely. Furthermore, the Wilcoxon test presents significant differences between both approaches for all the years.

Table 5. Descriptive statistics of the metafrontier efficiencies for both approaches

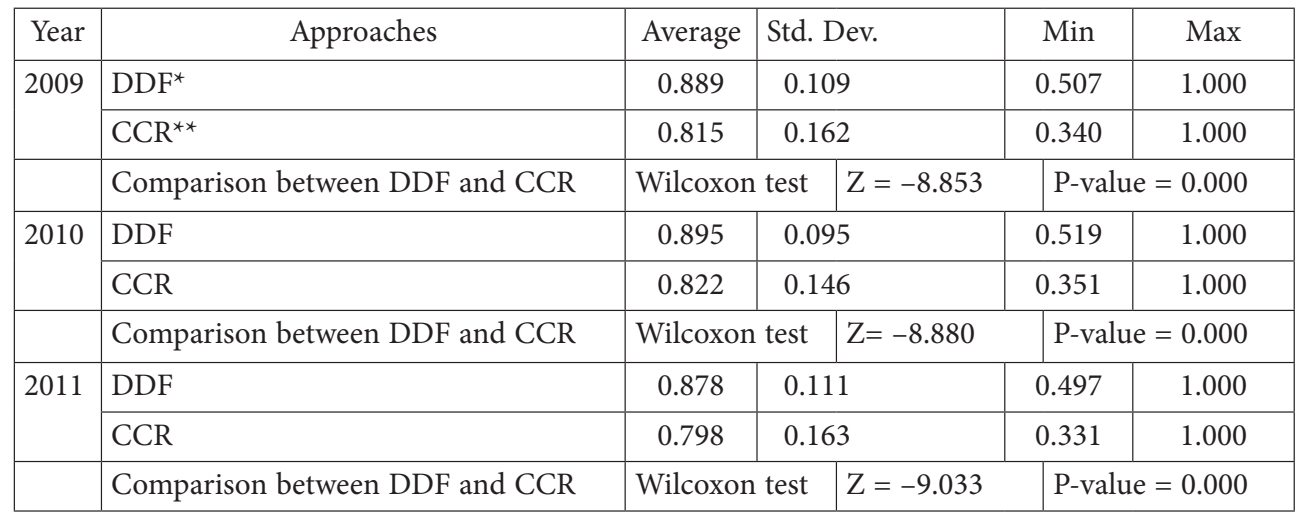

Notes: ${ }^{*}$ DDF: directional distance function ${ }^{*}$ CCR: input-oriented CCR model.

\subsection{Productivity measurement of metafrontier and group frontiers}

Using formulas (10) and (11), we obtain the Malmquist productivity indices (MMPI, GMPI) of the metafrontier and group frontiers. Table 6 and Table 7 illustrate the productivity indexes of the up-, middle- and downstream companies of the semiconductor industry from 2009 to 2010 and from 2010 to 2011. Table 6 shows that both the MMPI and the GMPI of IC packaging and testing companies rose (MMPI >1 and GMPI $>1$ ) from 2009 to 2010; while the productivity of IC design companies fell (MMPI $<1$ and GMPI $<1$ ); the metafrontier productivities of IC manufacturing companies fell (MMPI $<1)$, but their GMPI rose (GMPI $>1)$. To explore the reason why the productivity changes, looking at changes in pure technical efficiency, changes in scale efficiency and technical change, we found that, whether looking at the metafrontier or at group frontiers, the technical change in IC packaging and testing companies was greater than that in IC manufacturing companies, and both types of company show progress in technical change $\left(\mathrm{TC}^{m}>1, \mathrm{TC}^{k}>1\right)$; on the contrary, IC design companies show regression in technical change $\left(\mathrm{TC}^{m}<1, \mathrm{TC}^{k}<1\right)$. Additionally, the reason for the productivities of IC manufacturing companies being lower than those of IC packaging and testing companies is the low level of technical change in the metafrontier and group frontiers. 
From the viewpoint of the metafrontier, the scale efficiency change of IC design companies $\left(\mathrm{SEC}^{m v}=1.009\right)$ is the closest to 1 , which means that these companies are the closest to the optimum metafrontier production scale.

Using formula (15), we show that the differences between the MMPI and the GMPI lie in the catch-up in technology $\left(\mathrm{CUT}^{k, t, t+1}\right)$ and the potential technical changes $\left(\mathrm{PTC}^{k, t, t+1}\right)$. The values calculated for the potential technical changes of IC design companies are greater than unity, thus making the GMPI smaller than the MMPI. This shows that the production technology (productivity) of IC design companies in the group frontiers caught up with the production technology (productivity) in the metafrontier. However, the value of the catch-up in technology or potential technical changes is smaller than unity, thus making the GMPI greater than the MMPI. This means, in terms of measuring by group frontier, IC manufacturing companies and IC packaging and testing companies cannot catch up with the production technology (productivity) in the metafrontier.

Table 7 shows that, from 2010 to 2011, the MMPI and the GMPI of IC design, IC manufacturing, and IC packaging and testing companies all fell $(\mathrm{MMPI}<1$ and $\mathrm{GMPI}<1)$. Likewise, when exploring the productivity changes, looking at the change in pure technical efficiency, change in scale efficiency and technical change, we found that the cause of the overall productivity index decrease in the semiconductor industry is that the extent of the decrease in technical change is greater than the extent of the decrease in the change in pure technical efficiency, with the decrease in IC design companies being the most significant. The results show that the semiconductor industry began to move towards economic depression in 2011. From the viewpoint of the metafrontier, the scale efficiency change of IC design companies $\left(S E C^{m v}=0.998\right)$ is the closest to 1 , which shows that they are the closest to the optimum metafrontier production scale.

Using formula (15), we show that the differences between the MMPI and the GMPI lie in the catch-up in technology $\left(\mathrm{CUT}^{k, t, t+1}\right)$ and the potential technical changes $\left(\mathrm{PTC}^{k, t, t+1}\right)$. The catch-up in technology of IC manufacturing companies and the potential technological changes of IC design companies is smaller than unity, thus making the GMPI greater than the MMPI. This indicates that the production technology (productivity) of the semiconductor industry in the group frontiers cannot catch up with the production technology (productivity) in the metafrontier. However, the potential technological changes of IC packaging and testing companies lead to the GMPI being smaller than the MMPI. This shows that the production technology (productivity) of IC packaging and testing companies in the group frontiers caught up with the production technology (productivity) in the metafrontier.

Table 6. The decompositions of GMPI and MMPI from 2009 to 2010

\begin{tabular}{|l|c|c|c|c|c|c|c|c|c|c|c|c|}
\hline & MMPI & TEC $^{\mathrm{mv}}$ & SEC $^{\mathrm{mv}}$ & $\mathrm{TC}^{\mathrm{m}}$ & GMPI & TEC $^{\mathrm{kv}}$ & SEC $^{\mathrm{kv}}$ & TC $^{\mathrm{k}}$ & CUT $^{\mathrm{k}}$ & CUE $^{\mathrm{kv}}$ & CUS $^{\mathrm{k}}$ & PTC $^{\mathrm{k}}$ \\
\hline IC design & 0.750 & 1.012 & 1.009 & 0.737 & 0.748 & 1.014 & 1.008 & 0.735 & 0.999 & 0.998 & 1.001 & 1.003 \\
\hline $\begin{array}{l}\text { IC manufac- } \\
\text { turing }\end{array}$ & 0.848 & 1.090 & 0.963 & 0.813 & 1.232 & 1.040 & 1.004 & 1.180 & 1.006 & 1.047 & 0.960 & 0.723 \\
\hline $\begin{array}{l}\text { IC packaging } \\
\text { and testing }\end{array}$ & 1.317 & 1.014 & 0.959 & 1.367 & 1.468 & 1.008 & 0.971 & 1.512 & 0.994 & 1.007 & 0.988 & 0.908 \\
\hline
\end{tabular}


Table 7. The decompositions of GMPI and MMPI from 2010 to 2011

\begin{tabular}{|l|c|c|c|c|c|c|c|c|c|c|c|c|}
\hline & MMPI & TEC $^{\mathrm{mv}}$ & SEC $^{\mathrm{mv}}$ & $\mathrm{TC}^{\mathrm{m}}$ & GMPI & TEC $^{\mathrm{kv}}$ & SEC $^{\mathrm{kv}}$ & $\mathrm{TC}^{\mathrm{k}}$ & CUT $^{\mathrm{k}}$ & CUE $^{\mathrm{kv}}$ & CUS $^{\mathrm{k}}$ & PTC $^{\mathrm{k}}$ \\
\hline IC design & 0.624 & 0.986 & 0.998 & 0.636 & 0.628 & 0.985 & 0.997 & 0.641 & 1.002 & 1.001 & 1.001 & 0.993 \\
\hline $\begin{array}{l}\text { IC manufac- } \\
\text { turing }\end{array}$ & 0.707 & 0.924 & 0.992 & 0.772 & 0.740 & 0.987 & 0.989 & 0.764 & 0.937 & 0.935 & 1.005 & 1.272 \\
\hline $\begin{array}{l}\text { IC packaging } \\
\text { and testing }\end{array}$ & 0.724 & 0.985 & 1.015 & 0.725 & 0.618 & 0.995 & 1.009 & 0.616 & 0.997 & 0.990 & 1.007 & 1.151 \\
\hline
\end{tabular}

Table 6 and Table 7 compare the MMPI changes from the viewpoint of the up-, middle-, and downstream companies of the semiconductor industry. We then observe the trend over time of the MMPI when looking at the same group. From Table 8, we show that the productivity variation of the semiconductor industry sharply declined from 2009 to 2011, representing the occurrence of a new wave of economic recession. We found that the negative growth variation $(-0.451)$ of IC packaging and testing companies is greater than that of IC design companies $(-0.169)$ and IC manufacturing companies $(-0.166)$. Using the elements of the MMPI to explore the time trend of productivity changes, we found that the technical change $\left(\mathrm{TC}^{\mathrm{m}}\right)$ in IC design companies and IC packaging and testing companies was the main reason for the negative growth of the MMPI, meaning that, as time went by during the research period, technical change decreased. On the contrary, the pure technical efficiency change (TEC ${ }^{\mathrm{mv}}$ ) of IC manufacturing companies drives the negative growth of the MMPI, indicating that the pure technical efficiency of these companies drags down their productivity.

Table 8. The time trend of GMPI and MMPI from 2009 to 2011

\begin{tabular}{|l|c|c|c|c|c|c|c|c|c|}
\hline & \multicolumn{3}{|c|}{ IC design } & \multicolumn{3}{c|}{ IC manufacturing } & \multicolumn{2}{c|}{ IC packaging and testing } \\
\hline & $2009-$ & $2010-$ & $\begin{array}{c}\text { varia- } \\
\text { tion }\end{array}$ & $\begin{array}{c}2009- \\
2010\end{array}$ & $\begin{array}{c}2010- \\
2011\end{array}$ & $\begin{array}{c}\text { varia- } \\
\text { tion }\end{array}$ & $\begin{array}{c}2009- \\
2010\end{array}$ & $\begin{array}{c}2010- \\
2011\end{array}$ & $\begin{array}{c}\text { varia- } \\
\text { tion }\end{array}$ \\
\hline MMPI & 0.750 & 0.624 & -0.169 & 0.848 & 0.707 & -0.166 & 1.317 & 0.724 & -0.451 \\
\hline TEC $^{\mathrm{mv}}$ & 1.012 & 0.986 & -0.026 & 1.090 & 0.924 & -0.152 & 1.014 & 0.985 & -0.029 \\
\hline SEC $^{\mathrm{mv}}$ & 1.009 & 0.998 & -0.010 & 0.963 & 0.992 & 0.030 & 0.959 & 1.015 & 0.059 \\
\hline TC $^{\mathrm{m}}$ & 0.737 & 0.636 & -0.138 & 0.813 & 0.772 & -0.050 & 1.367 & 0.725 & -0.469 \\
\hline
\end{tabular}

\section{Conclusions and implementation}

Since the beginning of the twenty-first century, the semiconductor industry, which uses silicon as its main component, has increasingly been seen as one of the more important investments in the industrial development sector. Semiconductors are replacing oil and iron as the basics of industrial society. In response to the globalization trend, the semiconductor industry is under pressure to achieve low profit margins, and there is fierce competition, making its business performance particularly important. Therefore, this study analysed the static and dynamic business performances of IC design, IC manufacturing, and IC packaging and testing companies, the up-, middle- and downstream companies of the semiconductor 
industry, in order to provide directions for improving business performance through empirical results. We also discovered which companies have the best business efficiency and productivity within the semiconductor supply chain in Taiwan.

The empirical data used in this study were gathered from 111 semiconductor manufacturers that were listed on the stock market and the over-the-counter market in Taiwan from 2009 to 2011. The empirical results of this paper are summarized in the following paragraphs. First, the IC manufacturing companies underperformed from 2009 to 2011 against the IC design companies and IC packaging and testing companies when the metafrontier was regarded as the evaluation basis. From the perspective of TGR, IC design companies had the largest TGR, which means that IC design companies have the best ability to use their resources; they were followed by IC packaging and testing companies, and IC manufacturing companies were the worst in this category. Second, both the MMPI and the GMPI of IC packaging and testing companies rose (MMPI $>1$ and GMPI $>1$ ) from 2009 to 2010, while the productivities of IC design companies fell $(\mathrm{MMPI}<1$ and GMPI $<1)$. The metafrontier productivities of IC manufacturing companies fell (MMPI $<1)$, but their GMPI rose (GMPI>1). Third, between 2010 and 2011, the MMPI and the GMPI of IC design, IC manufacturing, and IC packaging and testing companies all fell $(\mathrm{MMPI}<1$ and $\mathrm{GMPI}<1)$. The results indicate that the semiconductor industry began to be affected by economic depression in 2011. Fourth, from the time trend of the MMPI, we discovered that the technical change of IC design companies and IC packaging and testing companies was the main reason for the negative growth of the MMPI. In contrast, the pure technical efficiency change of IC manufacturing companies caused the negative growth of their MMPI.

Next, we will be discussing the implications of the empirical results on the semiconductor industry in Taiwan. Through the study, we discovered that IC manufacturing requires considerable investment and then has the highest entry threshold within the semiconductor supply chain in Taiwan. On the contrary, IC design companies require low capital spending and an extensive use of human capital and intellectual capital industry. However, the global economy is good or bad has a very high interlocking relationship between the performances of the semiconductor market. In addition, capital spending in the semiconductor industry has still increased during the downturn in the global economy. The result is pointed out that some large semiconductor companies can continue to increase capital expenditures in the case of economic recession. Therefore, the semiconductor industry in Taiwan has faced the situation that the bigger the stronger in this fiercely competing market when the global economic recovery. After, the gap between competitors of the semiconductor industry will be widened and then the rise of the mergers and acquisitions will be generated.

\section{Limitations and recommendations}

Like other studies, this study has two limitations. First, this study was confined to data provided by the TEJ database, thus restricting the selection of business performance-related input and output variables for exploration. However, using information gathered from other databanks to enhance the data integrity, further studies may extend our study by considering other input or output variables, such as the number of patents and patent royalties. The number of patents and patent royalties are regarded as an important indicator of the outputs 
of R\&D (Hall, Ziedonis 2001; Hitt et al. 1991). Second, the semiconductor companies in this study don't consider the impact environmental variable on the semiconductor industry. We suggest adding related environmental variables in future research because of the environmental pollution produced in the process of manufacturing semiconductors. We recommend adding related undesirable output variables, such as effluent discharge, gas emission and waste disposal; this may lead to different results from those obtained in this study. Hence, future research could examine the environmental impact on performance evaluation in order to further enhance our understanding of underlying industry development.

\section{Acknowledgements}

This research was supported by the Ministry of Science and Technology (Taiwan) under contract NSC 103-2410-H-346-006. The authors are very grateful to the editor-in-chief and anonymous reviewers for detailed comments and helpful suggestions that greatly enhanced the quality of the paper.

\section{References}

Beck, R.; Wigand, R. T.; Konig, W. 2005. Integration of e-commerce by SMEs in the manufacturing sector: a data envelopment analysis approach, Journal of Global Information Management 13(3): 20-32. https://doi.org/10.4018/jgim.2005070102

Caves, D. W.; Christensen, L. R.; Diewert, W. E. 1982. The economic theory of index numbers and the measurement of input, output, and productivity, Econometrica: Journal of the Econometric Society 50(6): 1393-1414. https://doi.org/10.2307/1913388

Chang, P. L.; Tsai, C. T. 2002. Finding the niche position-competition strategy of Taiwan's IC design industry, Technovation 22(2): 101-111. https://doi.org/10.1016/S0166-4972(00)00093-6

Charnes, A.; Cooper, W. W.; Rhodes, E. 1978. Measuring the efficiency of decision-making units, European Journal of Operational Research 2(6): 429-444. https://doi.org/10.1016/0377-2217(78)90138-8

Chen, C. F.; Sewell, G. 1996. Strategies for technological development in South Korea and Taiwan: the case of semiconductors, Research Policy 25(5): 759-783. https://doi.org/10.1016/0048-7333(95)00861-6

Chen, C. J.; Chang, L. S. 2004. New product development strategy of IC design houses in Taiwan, Journal of American Academy of Business 5(1/2): 188-192.

Chen, C. J.; Wu, H. L.; Lin, B. W. 2006. Evaluating the development of high-tech industries: Taiwan's science park, Technological Forecasting and Social Change 73(4): 452-465. https://doi.org/10.1016/j.techfore.2005.04.003

Chen, K. H.; Yang, H. Y. 2011. A cross-country comparison of productivity growth using the generalised metafrontier Malmquist productivity index: with application to banking industries in Taiwan and China, Journal of Productivity Analysis 35(3): 197-212. https://doi.org/10.1007/s11123-010-0198-7

Chen, Y. S.; Chen, B. Y. 2011. Applying DEA, MPI, and grey model to explore the operation performance of the Taiwanese wafer fabrication industry, Technological Forecasting and Social Change 78(3): 536-546.

Chu, M. T.; Shyu, J. Z.; Khosla, R. 2008. Measuring the relative performance for leading fabless firms by using data envelopment analysis, Journal of Intelligent Manufacturing 19(3): 257-272.

https://doi.org/10.1007/s10845-008-0079-3 
Chung, Y. H.; Fare, R.; Grosskopf, S. 1997. Productivity and undesirable outputs: a directional distance function approach, Journal of Environmental Management 51: 229-240. https://doi.org/10.1006/jema.1997.0146

Eilat, H.; Golany, B.; Shtub, A. 2006. Constructing and evaluating balanced portfolios of R\&D projects with interactions: a DEA based methodology, European Journal of Operational Research 172(3): 1018-1039. https://doi.org/10.1016/j.ejor.2004.12.001

Färe, R.; Grosskopf, S.; Norris, M.; Zhang, Z. 1994. Productivity growth, technical progress, and efficiency change in industrialized countries, The American Economic Review 84: 66-83.

Graves, S. B.; Langowitz, N. S. 1996. R\&D productivity: a global multi-industry comparison, Technological Forecasting and Social Change 53(2): 125-137. https://doi.org/10.1016/S0040-1625(96)00068-6

Halkos, G. E.; Tzeremes, N. G. 2007. International competitiveness in the ICT industry: evaluating the performance of the top 50 companies, Global Economic Review 36(2): 167-182. https://doi.org/10.1080/12265080701374115

Hall, B. H.; Ziedonis, R. H. 2001. The patent paradox revisited: an empirical study of patenting in the US semiconductor industry, 1979-1995, Rand Journal of Economics 32: 101-128. https://doi.org/10.2307/2696400

Hitt, M. A.; Hoskisson, R. E.; Ireland, R. D.; Harrison, J. S. 1991. Effects of acquisitions on R\&D inputs and outputs, Academy of Management Journal 34: 693-706. https://doi.org/10.2307/256412

Hsiao, F. S. T.; Park, C. 2005. Korean and Taiwanese productivity performance: comparisons at matched manufacturing levels, Journal of Productivity Analysis 23(1): 85-107. https://doi.org/10.1007/s11123-004-8549-x

Hsu, C. W.; Chiang, H. C. 2001. The government strategy for the upgrading of industrial technology in Taiwan, Technovation 21(2): 123-132. https://doi.org/10.1016/S0166-4972(00)00029-8

Hsu, F. M.; Horng, D. J.; Hsueh, C. C. 2009. The effect of government-sponsored R\&D programmes on additionality in recipient firms in Taiwan, Technovation 29(3): 204-217. https://doi.org/10.1016/j.technovation.2008.05.001

Hsu, L. C. 2015. Using a decision-making process to evaluate efficiency and operating performance for listed semiconductor companies, Technological and Economic Development of Economy 21(2): 301-331. https://doi.org/10.3846/20294913.2013.876689

Huang, C. W.; Chiu, Y. H.; Lin, C. H.; Liu, H. H. 2012. Using a hybrid systems DEA model to analyze the influence of automatic banking service on commercial banks' efficiency, Journal of the Operations Research Society of Japan 55(4): 209-224.

Hung, S. W.; He, D. S.; Lu, W. M. 2014. Evaluating the dynamic performances of business groups from the carry-over perspective: a case study of Taiwan's semiconductor industry, Omega - The International Journal of Management Science 46: 1-10. https://doi.org/10.1016/j.omega.2014.01.003

Hung, S. W.; Lu, W. M. 2008. The comparative productivity efficiency of Taiwan's integrated circuits packaging/testing firms, INFOR: Information Systems and Operational Research 46(3): 189-198. https://doi.org/10.3138/infor.46.3.189

Kao, C. 2009. Efficiency decomposition in network data envelopment analysis: a relational model, European Journal of Operational Research 192(3): 949-962. https://doi.org/10.1016/j.ejor.2007.10.008

Kao, L. J.; Lu, C. C.; Chiu, C. C. 2011. The training institution efficiency of the semiconductor institute programme in Taiwan - application of spatiotemporal ICA with DEA approach, Journal of the Operational Research Society 62(12): 2162-2172. https://doi.org/10.1057/jors.2010.177

Kozmetsky, G.; Yue, P. 1998. Comparative performance of global semiconductor companies, Omega The International Journal of Management Science 26(2): 153-175.

Lee, C. Y.; Johnson, A. L. 2011. A decomposition of productivity change in the semiconductor manufacturing industry, International Journal of Production Research 49(16): 4761-4785. https://doi.org/10.1080/00207543.2010.497507 
Liu, F. H. F.; Wang, P. 2008. DEA Malmquist productivity measure: Taiwanese semiconductor companies, International Journal of Production Economics 112(1): 367-379. https://doi.org/10.1016/j.ijpe.2007.03.015

Lu, W. C. 2009. The evolution of R\&D efficiency and marketability: evidence from Taiwan's IC-design Industry, Asian Journal of Technology Innovation 17(2): 1-26. https://doi.org/10.1080/19761597.2009.9668671

Lu, W. M.; Hung, S. W. 2010. Assessing the performance of a vertically disintegrated chain by the DEA approach-a case study of Taiwanese semiconductor firms, International Journal of Production Research 48(4): 1155-1170. https://doi.org/10.1080/00207540802484929

Lu, W. M.; Wang, W. K.; Tung, W. T.; Lin, F. 2010. Capability and efficiency of intellectual capital: the case of fabless companies in Taiwan, Exper Systems with Applications 37(1): 546-555. https://doi.org/10.1016/j.eswa.2009.05.031

Mahadevan, R. A. 2002. A DEA approach to understanding the productivity growth of Malaysia's manufacturing industries, Asia Pacific Journal of Management 19: 587-600. https://doi.org/10.1023/A:1020577811369

Meng, W.; Hu, Z.; Liu, W. 2006. Efficiency evaluation of basic research in China, Scientometrics 69(1): 85-101. https://doi.org/10.1007/s11192-006-0140-y

Nazarko, J.; Šaparauskas, J. 2014. Application of DEA method in efficiency evaluation of public higher education institutions, Technological and Economic Development of Economy 20(1): 25-44. https://doi.org/10.3846/20294913.2014.837116

O’Donnell, C. J.; Rao, D. S. P.; Battese, G. E. 2008. Metafrontier frameworks for the study of firm-level efficiencies and technology ratios, Empirical Economics 34(2): 231-255.

Oh, D. H. 2010. A global Malmquist-Luenberger productivity index, Journal of Productivity Analysis 34(3): 183-197. https://doi.org/10.1007/s11123-010-0178-y

Oh, D. H.; Lee, J. 2010. A metafrontier approach for measuring Malmquist productivity index, Empirical Economics 38(1): 47-64. https://doi.org/10.1007/s00181-009-0255-0

O'Mahony, M.; Vecchi, M. 2009. R\&D, knowledge spillovers and company productivity performance, Research Policy 38(1): 35-44.

Seiford, L.; Zhu, J. 1999. Profitability and Marketability of the Top 55 US Commercial Banks, Management Science 45(9): 1270-1288.

Shen, K. Y.; Tzeng, G. H. 2016. Combining DRSA decision-rules with FCA-based DANP evaluation for financial performance improvements, Technological and Economic Development of Economy 22(5): 685-714. https://doi.org/10.3846/20294913.2015.1071295

Sterlacchini, A. 1999. Do innovative activities matter to small firms in non-R\&D-intensive industries? An application to export performance, Research Policy 28(8): 819-832. https://doi.org/10.1016/S0048-7333(99)00023-2

Taiwan Semiconductor Yearbook. 2012. Taiwan Industrial Technology Research Institute. Hsinchu, Taiwan (in Chinese).

Thore, S.; Phillips, F.; Ruefli, T.; Yue, P. 1996. DEA and the management of the product cycle: the US computer industry, Computers and Operations Research 23(4): 341-356. https://doi.org/10.1016/0305-0548(95)00043-7

Wang, E. C.; Huang, W. 2007. Relative efficiency of R\&D activities: a cross-country study accounting for environmental factors in the DEA approach, Research Policy 36(2): 260-273. https://doi.org/10.1016/j.respol.2006.11.004

Wu, W. Y.; Tsai, H. J.; Cheng, K. Y.; Lai, M. 2006. Assessment of intellectual capital management in Taiwanese IC design companies: using DEA and the Malmquist productivity index, $R \& D$ Management 36(5): 531-545. https://doi.org/10.1111/j.1467-9310.2006.00452.x 